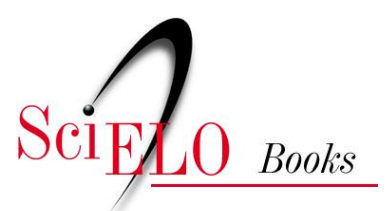

\title{
Experiencias de buenas prácticas 6. La incorporación de las TIC en el aprendizaje. Mejoramiento de la calidad de vida (testimonio)
}

\author{
Pablo Laverde \\ Miriam Gallegos \\ Jessica Rivadeneira
}

\section{SciELO Books / SciELO Livros / SciELO Libros}

LAVERDE, P., GALLEGOS, M., and RIVADENEIRA, J. La incorporación de las TIC en el aprendizaje. Mejoramiento de la calidad de vida (testimonio). In: GALLEGOS NAVAS, M., ed. $L a$ inclusión de las TIC en la educación de personas con discapacidad: relatos de experiencias [online]. Quito: Editorial Abya-Yala, 2019, pp. 103-116. ISBN: 978-9978-10-495-8. https://doi.org/10.7476/9789978104958.0009.

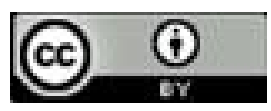

All the contents of this work, except where otherwise noted, is licensed under a Creative Commons Attribution 4.0 International license.

Todo o conteúdo deste trabalho, exceto quando houver ressalva, é publicado sob a licença Creative Commons Atribição 4.0.

Todo el contenido de esta obra, excepto donde se indique lo contrario, está bajo licencia de la licencia $\underline{\text { Creative }}$ Commons Reconocimento 4.0. 


\section{La incorporación de las TIC en el aprendizaje. Mejoramiento de la calidad de vida (testimonio)}

"La ciencia y la tecnología, en la sociedad revolucionaria, deben estar al servicio de la liberación permanente de la Humanización del hombre" (P. Freire)

Universidad Politécnica Salesiana

Ecuador

Quito

Responsable: Pablo Laverde

En esta experiencia presento mi testimonio personal en el que se deja establecido el hecho de que la tecnología se vuelve una aliada para la superión personal

\section{Motivación}

La condición de discapacaidad, no impede desarrollar sueños personales como es el de escribir y transmitir a través de sus textos, el pensamiento propio, logrando así objetivos personales y profesionales.

Figura 44

Pablo Laverde, "Programador Matemático"

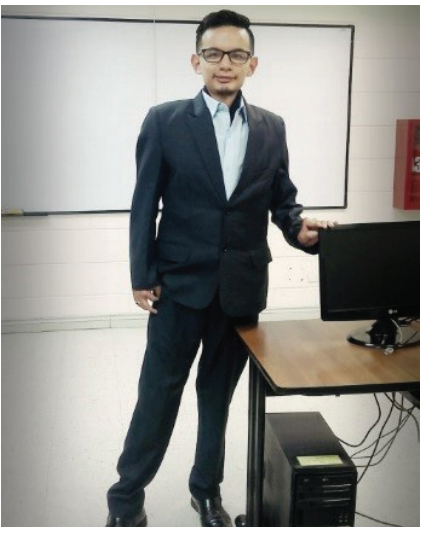

Foto: Pablo Laverde (2016) 
104

En mi condición de persona con discapacidad física producto de una distrofia muscular, el acceso a la información y comunicación a través de recursos tecnológicos constituyen mi principal apoyo para potenciar mi aprendizaje y mis actividades cotidianas; mi computadora se ha convertido en mi amiga permanente ya que gracias a ella plasmo toda mi producción intelectual con mayor facilidad en menos tiempo; me gusta escribir con el fin de influir en el pensamiento de los jóvenes para que encuentren sentido a su vida, además, disfruto liderando grupos de juveniles, y gracias al internet puedo investigar y ampliar mi conocimientos y llegar más allá de lo que mis limitaciones físicas me lo permiten. La práctica cuenta con la participación de mis padres, mi persona y mis treinta compañeros de clase.

\section{Desarrollo de la experiencia}

En pequeños recuerdos que bordean mi pensamiento, están presentes aquellos días en los cuales mi querida madre con lágrimas en los ojos en un hospital escuchaba el diagnóstico de un doctor que decía con una segura precisión; su hijo tiene una discapacidad física, no podrá llevar una vida normal y le queda poco tiempo de vida, siendo un niño de 5 años no sabía a lo que se refería, solo estaba preocupado porque no podía jugar fútbol con mis primos o correr para alcanzar a mis compañeros de la escuela, quería ir rápido a casa para jugar con mi mascota, pero seguíamos escuchando al doctor y en palabras de médico contaba que 1 de cada 1000 niños en el mundo nacen con una discapacidad como la de su hijo y el 90\% fallece a la edad de 12 años, recomendó fisioterapia para aumentar de alguna manera la masa muscular, su recetario estaba vacío ya que dijo que no existía medicina para curar esta enfermedad.

Con el pasar del tiempo en mi escuela la solidaridad de mis compañeros se hacía presente brindándome un espacio de inclusión social, estaban dispuestos a ayudarme a movilizarme en los diferentes espacios de la institución, también jugaban y estaban conmigo en todo momento sin dejarme solo. Esto me ayudó a darme cuenta que no hay limitacio- 


\section{5}

nes para compartir las experiencias de la vida con las personas que estaban pendientes de mí, que de alguna manera cuando caía me ayudaban a levantarme y mantenerme firme con mis propósitos.

\section{Figura 45}

Apoyo incondicional de la madre

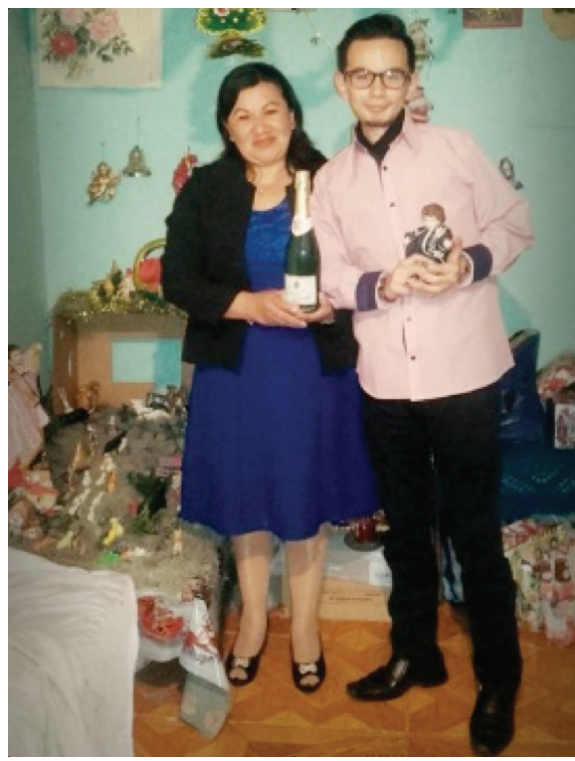

Foto: Pablo Laverde (2016)

Mi madre, constantemente decía que tenga cuidado ya que caía de vez en cuando y mis rodillas se raspaban, pero en mi mente estaban presentes las ganas de seguir con la misma actividad. Sus cuidados hasta el día de hoy son permanentes, no permitía que haga cosas que provoquen daños en mi persona; durante toda mi vida ella ha sido el pilar fundamental de las acciones que realizaba, solía repetirme que piense antes de hacer las cosas y que todo en la vida pasa por algo; una persona tan religiosa como ella determinaba que Dios era el que definía dos caminos nuestro destino y que nosotros solo somos quienes decidimos cual de los dos tomar, el 
106

fácil, sin nada de represión ni sufrimiento y el difícil, en el cual existen barreras y distintos riesgos a tomar para seguirlo; con tan solo 8 años de edad solo entendía que si tomaba el camino fácil no lograría nada en la vida, pero si me portaba valiente y seguía el difícil algún día después de tantos obstáculos tendría nuevas metas para seguir adelante.

Mis profesores llegaron a tenerme aprecio, me veían como un buen estudiante que salía adelante y perseguía sus sueños sin importar la condición en la que estaba expuesto. Sin embargo, mis pasos con el tiempo se fueron haciendo más pesados y en mi mente seguía viva la imagen de aquel doctor que expuso el periodo corto de vida que tenía; además, que en poco tiempo necesitaría una silla de ruedas para poder movilizarme siempre, yo no hacía más que pensar que sentado para siempre en una silla de ruedas la vida a la que estaba acostumbrado cambiaría radicalmente y mis sueños que perseguía con anhelo se verían afectados, eran aquellos pensamientos que tenía cuando era niño y que con el tiempo llegando a la madurez irían cambiando.

Figura 46

Gusto por la Literatura

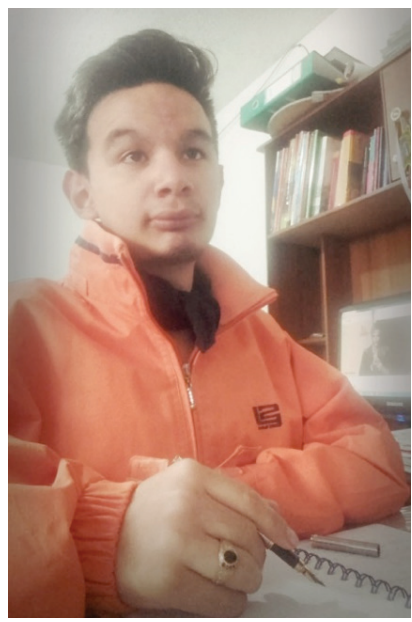


Cuando mis manos apretaban el lápiz y tenía una hoja en mi mesa me sentía poderoso ya que las tareas eran lo más simple en mi vida, terminaba rápido y buscaba seguir escribiendo o dibujando, me sentía muy bien porque expresaba lo que sentía en lo que hacía en esos momentos, me inundaba la felicidad ya que redactando me olvidaba de la silla de ruedas, me concentraba en hacer desde unas simples sumas hasta complejas divisiones que en la escuela me enseñaban; cuando me ponía triste no había nada más que me pusiera de buen humor guardar muy bien mis apuntes, como un tesoro escondido en una isla misteriosa, parecía que algún día esos papeles me harían mucha falta; y fue así, cada vez que me insistían que tenía que estar en una silla de ruedas los leía y salía caminando a jugar con mis primos, jugar definitivamente me hacía bien y después me sentía más fuerte e inevitablemente quería seguir escribiendo lo que sentía.

Con el pasar del tiempo constantemente en la primaria subía de nivel con buenas notas, las felicitaciones de mi familia y maestros no se hacían esperar, eres un muy buen niño, decían y lo repetían cuando me veían triste por algo que no podía hacer o cuando con mis pocas fuerzas me sentía desalentado y sin ganas de continuar.

Llegaron los niveles altos en la escuela y conocí algo tan bonito llamado computadora, eran unas máquinas donadas por el Ministerio de Educación y tenían juegos interactivos que ayudaban en la educación de los estudiantes, lo que más me llamaba la atención fue cuando mi maestro de computación me indicó que existía un programa para escribir cualquier cosa, el famoso Word, en mi mente solo estaba la idea de escribir algo bonito para una niña que me gustaba, procedí a prender la computadora y con el puntero del mouse abrí el programa en su versión 2003 una hoja en blanco y unas opciones en la parte de arriba eran las características de aquel programa lo que más me llamó la atención era que tecleando las letras, estas aparecían en la hoja en blanco y con las herramientas de la parte superior podía cambiar de color las letras o elegir el tipo de las mismas a mi gusto; fue entonces cuando comencé a realizar la carta para aquella niña por la cual sentía algo especial cuando la veía. 
La moda de las computadoras crecía, y los profesores comenzaban a enviar deberes en computadora, fue entonces cuando al no contar con una computadora en casa tenía que ir al centro de cómputo más cercano para poder hacer las tareas encomendadas, la afición que sentía al manejar aquella máquina crecía y las ganas de seguir aprendiendo eran persistentes; además, Word ya no me llamaba la atención ya que nos habían enseñado todo sobre aquel programa y quería aprender cosas nuevas.

Una clase de computación de dos horas en un día como cualquiera marcó la diferencia, el maestro indicó que ya no manejaríamos Word ni Excel ya que con los conocimientos que teníamos era suficiente para hacer cualquier tipo de documento, pidió que prendamos la computadora y hagamos doble clic en el ícono Internet Explorer al abrir aquel programa de internet unas letras grandes y coloridas que decían Google y más abajo una parte para escribir algo apareció, el maestro indicó que este es un navegador y que se puede buscar cualquier cosa, en ese instante me invadió la duda de cómo funciona el programa, y procedí a escribir la palabra juegos, de repente se desplegó una página con algunos títulos de color azul, el profesor indicó que haciendo clic en cualquiera de los títulos se desprende información o algo en específico de lo que buscábamos, el profesor nos dio una hora para hacer un documento en Word sobre algún tema en especial no lo pensé mucho y escogí distrofia muscular espinal muchos textos hablaban sobre esta enfermedad, se presentaban imágenes de niños en sillas de ruedas niños postrados en camas con cables y tubos de respiración; mirando estas imágenes me inundó un sentimiento de angustia, pero tenía que hacer la tarea propuesta, de repente al leer un artículo sobre la enfermedad una imagen me llamó mucho la atención era un señor sentado en una silla de ruedas con la mirada al piso y algunas malformaciones en su cuerpo, se trataba de un científico reconocido mundialmente por su aportes a la ciencia, Steven Hawking, leer su vida y logros cambiaron mi enfoque de la discapacidad y me ayudó a vencer mis miedos para ser como aquel científico cuya incapacidad lo llevó a ser quien es ahora. 
Continué con mis estudios con tranquilidad y afición, hasta que a la edad de 11 años en un mes de mayo una semana después de celebrar el sacramento de la Primera Comunión una triste situación invadió a mi familia, mi hermano mayor de 24 años falleció en un accidente, fue tan lamentable la noticia que mi madre sentía que una parte de su corazón se arrancaba dolorosamente y lo sepultaba en un frío cementerio, por mi parte solo sentía que ya no compartiría los más grandiosos momentos de alegría y juegos con el hermano que estaba conmigo en todo momento, tenía otro hermano mayor que vivía lejos y casi no lo veía al ver tan dolorosa situación se mudó con nosotros hasta que la tormenta pase.

El tiempo pasaba, los tristes sentimientos que tenía por la muerte de mi hermano comenzaron a ser menos constantes. En mi pensamiento permanecían vigentes recuerdos de lo que pasó, pero no podía dejar de lado mis estudios. Me convertí en aquella persona que no deja de lado algo que quiere hacer y hace hasta lo imposible por lograrlo. Mi hermano descansaba en paz, mi madre se recuperaba con psicólogos, mi otro hermano hacía planes de viaje y mi padre se alejó de nosotros, la única manera de dejar de lado esas situaciones fue haciendo lo que tenía que hacer, continuar mis estudios.

Felicitaciones, siga adelante; mis cuadernos de primaria se llenaban de aquellos sellos tan agraciados de caritas felices o tristes de profesores de mi escuelita percibía una gran satisfacción cuando mis notas eran sobresalientes cuando por alguna razón, las notas bajaban me angustiaba un poco pero me llenaba de fuerza y recuperaba aquellas notas ejercitando mi mente y volviendo a intentarlo, como algunas situaciones en la vida en el segundo intento recuperaba lo que deseaba y mi pensamiento ya no se ocupaba de las cosas que no podía hacer por mi enfermedad, sino por las que puedo lograr con mis estudios.

Una computadora en mi casa con internet me permitía hacer tareas e investigaciones que me ayudaban a entender el contexto de mis estudios y lo que pasaba alrededor del mundo; un adolescente es atraído 


\section{0}

por la música y videos que distraían su mente, yo no me quedaba atrás; tomaba momentos para todo y organizaba cada tarea que debía hacer, eso ayudaba a que mis estudios sobre las matemáticas surjan, escribía algunos ensayos que describían la importancia de las matemáticas en los estudios y cuando podía redactaba algunos poemas que afloraban los sentimientos de adolescente.

\section{Logros obtenidos}

Figura 47

Discursos presidenciales

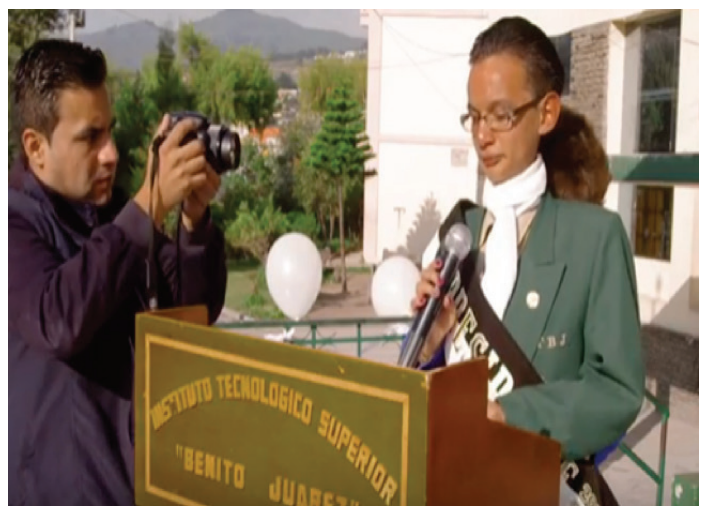

Foto: Pablo Laverde (2016)

El gusto de toda mi familia fue cuando en décimo año de educación básica, fui proclamado abanderado. Me alegré mucho cuando por primera vez en mi vida con mis pocas fuerzas pude levantar la bandera. De repente me sentía feliz y en un discurso agradecí a Dios, a mi madre, a mi familia, a mis amigos y a quienes hicieron realidad este sueño. No había logrado tanto éxito sin el apoyo de todos ellos. La maestra de matemáticas que había sido mi docente durante tres años consecutivos se acercó a felicitarme y de repente vi una lágrima que corría por su mejilla, le pregunté, ¿Por qué estaba triste? y me respondió, llevo 10 años 
siendo maestra en este colegio y es la primera vez que tengo a un alumno como tú, lamentablemente por situaciones personales tengo que ir a trabajar en otro colegio. En mi mente estaba por decirle que no se fuera porque era la persona que más me apoyaba, pero solo pude responder al abrazo, entonces me contestó; sigue siendo como eres, no cambies.

Era un arduo trabajo ser estudiante y líder de más de 3000 estudiantes, pero tuve un apoyo incondicional del Consejo Nacional Electoral quién en una ceremonia me reconoció como el mejor líder estudiantil; me apasionaba el hecho de participar en todo tipo de reuniones y eventos que contribuían al desarrollo de la educación, fue entonces cuando al momento de realizar mi monografía, redacté un capítulo de la belleza y elegancia de las matemáticas. Era el momento de implementar de manera más eficiente el desarrollo tecnológico, entonces comencé con un gusto por la programación y el diseño de proyectos en programas que permitían que mis ideales sean reconocidos, es por eso que implemente el tema de Belleza y elegancia de las Matemáticas, un conjunto de escritos que gracias a la práctica en computadoras y dispositivos los ponía a disposición de las personas interesadas en conocer sobre el tema; uno de los escritos refería que:

La matemática es elegante, una noble ciencia que ayuda a la comprensión de la razón del ser y el existir; es dotada de gracia, su resolución mueve al mundo por conseguir resultados sobre sus problemas, algo que resulta grandioso, ya que unifica pueblos y naciones, que resuelven conflictos con números y letras; es sencilla, para su resolución solo basta un conocimiento pleno, sobre sus fundamentos, relacionándola con las demás ciencias, es la más detallada, infalible, rigurosa, precisa, exacta y comprobada (Laverde, 2015).

Basándome en aquella pasión por escribir lo que tenía en mente tuve la oportunidad de seguir adelante con mis estudios en la educación superior. 


\section{2}

Figura 48

Inicios en la Universidad

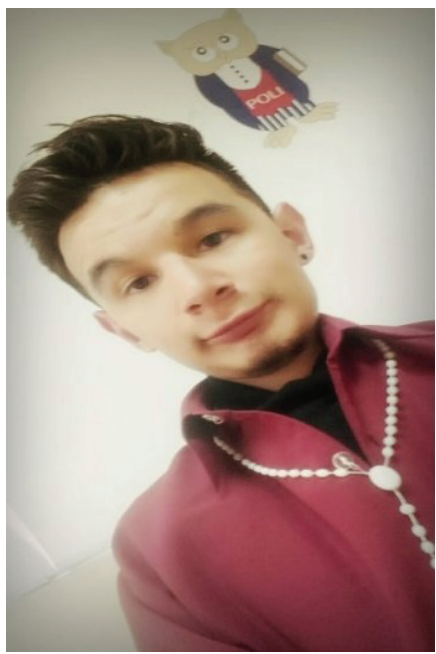

Foto: Pablo Laverde (2016)

El siguiente paso de la educación fue la universidad, en las pruebas de la Secretaría de Educación Superior, Ciencia, Tecnología e innovación (SENESCYT) fui admitido en la Escuela Politécnica Nacional, en la carrera de Ingeniería Matemática, ahí durante dos semestres aprendí a demostrar varios teoremas que pasan desapercibidos en el Estudio de las Matemáticas. Por diferentes situaciones comprendí que para desarrollar a plenitud estos estudios es necesario aprender primero a formalizar una ciencia que busque promover nuevas tendencias en el presente y futuro; la Ingeniería en Ciencias de la Computación sería la base fundamental, así que tomé la decisión de estudiar aquella carrera para seguir adquiriendo conocimiento científico y llegar a la meta planificada.

Sin duda la universidad es un nuevo espacio de creación de conocimiento, en donde los jóvenes aprendemos que las metas propuestas por uno mismo son aquellas que se logran con esfuerzo y dedica- 
ción; mi propuesta hacia la educación superior radica en el servicio a los demás y el compartir mis experiencias como ser humano hacia el mundo, sin dejar de lado la teoría de la capacidad de cada persona para seguir adelante con sus sueños, además, un joven con determinación es el factor clave para dar solución por lo menos a algún problema en el mundo; me encaminé a cambiar el mundo paso a paso, en la universidad fundamentando mis conocimientos y aprendiendo cada día a saber demostrarlos en un futuro próximo, la razón de estudiar una carrera tan compleja como la Ingeniería es por demostrar a la sociedad que no hay barreras que impidan seguir cultivando sueños y cosechando éxitos que valen la pena.

El ambiente universitario está más definido en lo que se hace para aprobar la carrera, la institución brinda los soportes necesarios para continuar, entonces hay que aprovecharlos al máximo si una persona con discapacidad se encuentra con estos; las rampas digitales se hacen presentes y son de mucha ayuda al momento de hacer un trabajo que tenga una gran dificultad, para quienes tenemos discapacidad motriz la ayuda de programas como: Técnica de Estudio, un software de refuerzo para mejorar actividades como: concentración, ambiente de estudio, actitud, técnicas, memoria y razonamiento; In-Tic, un programa que tiene como objetivo ayudar a mejorar la autonomía personal creando entornos personalizados para un acceso simplificado a computadoras y a celulares, además, de funcionar como un comunicador dinámico; entre otros, son de gran importancia para enfrentarse con las distintas situaciones que surgen al momento de cursar una carrera, en lo personal me han ayudado a tener mayor capacidad de comunicación.

Según la Unesco:

Las TIC no abarcan sólo dispositivos como computadoras, radios, teléfonos celulares y conectividad, sino que también remiten a la posibilidad que se abre a las personas de crear, compartir y adquirir conocimientos. Para colmar la "brecha digital" se hacía hincapié inicialmente en la instalación de equipos e infraestructura informáticos y la garantía 
114

del acceso y la conectividad. Sin embargo, la UNESCO siempre ha subrayado la importancia de los componentes "intangibles" de las TIC, es decir las dimensiones del contenido, las políticas y el desarrollo de capacidades, que son igualmente fundamentales para colmar esa brecha (Unesco, 2012).

Una situación de la vida actual está caracterizada en lo que haces, para qué lo haces y para quiénes lo haces, ya sea con herramientas tan sutiles como el manejo de computadoras y otros dispositivos que permiten la interacción del ser humano con la tecnología y la ciencia, únicamente en un sentido ético, queda por decir, que la tecnología es de gran importancia para desarrollar las habilidades de personas que pudieran quedarse en el olvido por una discapacidad que lo marcó de por vida.

La importancia de las TIC en la discapacidad es una solución a aquellas situaciones en las cuales las personas quieren ver sus sueños hechos realidad, pero, no solo se trata de computadoras que trabajan al ritmo de la situación en la que se vive para salir adelante, en efecto el mundo de la tecnología en el cual estamos viviendo da a conocer las diferentes soluciones hechas por programadores y personas que están trabajando a diario por la implementación de un mundo incluyente para todos. Ahora bien, si hablamos de la inclusión es necesario debatir el tema de la capacidad de las personas para hacer diferentes actividades y aquellas actividades que no son posibles de realizar pero que se pueden implementar de manera efectiva. No sólo es el hecho significativo de hacer tecnología que apoye al descubrimiento de capacidades y la ayuda con respecto a la discapacidad, sino también es necesario conocer la manera efectiva de presentar aquella tecnología con fundamentos esenciales para toda persona, independiente de que pueda o no manejar tecnología.

Vivir los sueños de un joven con discapacidad motriz, cuyas metas están encaminadas al servicio social es una ligera ilusión vista a los ojos de quienes tienen todas sus capacidades y no las aprovechan y no es el hecho de que los impedimentos físicos determinen la falta de las 
ganas de luchar por conseguir de alguna manera aquel sueño, al parecer el poder del ser humano radica esencialmente en lo que se propone hacer, y hablando en un plano más antropológico la esencia pura de sus dimensiones al realizar sus actividades como acostumbra; generalmente nos vemos en la situación de impotencia ante lo difícil que se presenta en la vida, pero qué sería del mundo si la impotencia hubiese ganado a aquellos científicos, investigadores o artistas que no se dejaron llevar por las dificultades y dieron al mundo grandes innovaciones que permitieron el desarrollo de la sociedad, algo increíble ¿verdad?, y fue aquel pensamiento el que me permitió ir más allá de mis límites y hacer algo que promueva el sentido de amor a lo que hago cada día y la gratitud con los demás por permitirme enfocarme en nuevas visiones a través de la tecnología.

De cierta forma los recursos tecnológicos enfocados para la discapacidad motriz como gadgets, software especializado, sillas de ruedas electrónicas, recursos digitales con precisión para realizar tareas cotidianas, entre otros; ayudan de manera efectiva a que la persona que utiliza estos implementos lleve una vida parcialmente normal; en mi caso estos recursos serán indispensables a medida que se eleve el grado de dificultad para realizar acciones; no obstante, como ya lo había mencionado el uso del computador con herramientas que ayudan a la realización de programas e implementos que ayuden de alguna manera a la inclusión de personas con discapacidad en todos los ámbitos de la vida, ahí uno de mis objetivos. Queda claro que la tecnología en mi vida se ha presentado como el instrumento de gran utilidad para erradicar el pensamiento de impotencia y elevar aquellas facultades escondidas del ser humano y seguir una evolución continua con éxito y perseverancia.

Ahora bien, es necesario que estos implementos sean determinados con el estudio de determinadas ciencias que son parte fundamental de la tecnología, es por eso que durante mis estudios universitarios como en las investigaciones que estoy llevando a cabo, iré descubriendo nuevos métodos que ayuden con los objetivos propuestos, además, inte- 
resado por la literatura y el arte de creación de conciencia hacia aquellas personas que necesiten de apoyo emocional "No descansaré de escribir hasta que mis palabras se plasmen en la vida de los jóvenes" quienes serán los que seguirán apoyando la inclusión y las ganas inevitables de seguir siempre adelante a pesar de cualquier dificultad.

\section{Proyecto "Sígueme" una iniciativa para apoyar a estudiantes con Trastornos del Espectro Autista}

"El trabajo del maestro no consiste tanto en enseñar todo lo aprendible, como en producir en el alumno amor y estima por el conocimiento"

(John Locke)

Instituto de Educación Especial del Norte

Ecuador

Quito

Responsable: Giovanna Bedoya Navas

Gestores : Área Psicológica de la institución

Con la ejecución de este proyecto innovador se promueve el desarrollo de habilidades sociales de los estudiantes con Trastornos del Espectro Autista (TEA) de bajo funcionamiento que acuden a la institución, instaurando con la ayuda de programas informáticos rutinas de trabajo que comprometen la necesidad de compartir con otros y fomentando la interrelación social.

\section{Motivación}

Esta práctica se desarrolla en el Instituto de Educación Especial del Norte en la ciudad de Quito, con estudiantes con Trastorno del Espectro Autista de bajo funcionamiento, cuyas barreras en la comunicación limitan el logro de aprendizajes académicos y sociales.

Los docentes de la institución manifiestan la dificultad que tienen para controlar la conducta de los estudiantes en el aula, por lo tanto los remiten al servicio de psicología para que reciban los apoyos correspondientes. 